\title{
Protocolo de um banco de tecidos neoplásicos*
}

\author{
Protocol for a tumor tissue bank
}

\author{
Luiz José Moura Alimena', Reynaldo Jesus-Garcia Filho², Silvia Regina Caminada de Toledo³, \\ Maria Teresa de Seixas Alves ${ }^{4}$, Antonio Sergio Petrilli ${ }^{5}$, Giuseppe De luca Junior ${ }^{6}$, \\ LUCAS SENGER JACOBUS ${ }^{6}$, RICARDO FILIPE ROMANI ${ }^{7}$, DANIEL LUNARDI SPADER ${ }^{7}$
}

\section{RESUMO}

Um banco de tumores com organização sistematizada das informações permite a elaboração de pesquisas em câncer com conclusões sólidas e científicas. Assim, há a necessidade de um protocolo específico, cuja principal vantagem seria a de agre-

* Trabalho realizado no Departamento de Oncologia e no Instituto de Oncologia Pediátrica - IOP-GRAACC da Universidade Federal de São Paulo - UNIFESP - São Paulo (SP), Brasil.

1. Mestre em Medicina pela Escola Paulista de Medicina; Médico Traumatologista e Ortopedista do Setor de Ortopedia Oncológica da Santa Casa de Porto Alegre, Porto Alegre (RS), Brasil.

2. Livre-Docente, Professor Associado do Departamento de Ortopedia da Universidade Federal de São Paulo; Chefe do Setor de Ortopedia Oncológica da Disciplina de Ortopedia - UNIFESP São Paulo (SP), Brasil.

3. Doutora, Professora da Universidade Federal de São Paulo; Coordenadora do Laboratório de Genética do Instituto de Oncologia Pediátrica GRAACC/UNIFESP - São Paulo (SP), Brasil.

4. Doutora, Professora da Universidade Federal de São Paulo; Chefe da Disciplina Anatomia Patológica Geral, Sistêmica, Forense e Bioética, São Paulo (SP), Brasil.

5. Livre-Docente, Professor da Universidade Federal de São Paulo. Diretor Geral Instituto de Oncologia Pediátrica, São Paulo (SP), Brasil.

6. Acadêmico de Medicina da Fundação Faculdade de Ciências Médicas de Porto Alegre - FFFCMPA - Porto Alegre (RS), Brasil.

7. Acadêmico de Medicina pela Universidade Federal do Rio Grande do Sul - UFRGS - Porto Alegre (RS), Brasil.

Endereço para correspondência: Luiz Alimena, Rua Antonio Parreiras, 339/402 - 90450-050 - Porto Alegre, RS. Tel.: (51) 33310456. E-mail: alimena.1@terra.com.br

Copyright RBO2008 gar informações qualificadas sobre o doador às amostras tumorais utilizadas para a pesquisa. $O$ objetivo deste trabalho foi desenvolver um protocolo de procedimentos simples, confiável e reproduzível, para adquirir e armazenar amostras de tumores do sistema músculo-esquelético. O planejamento deste protocolo tem como base os dados da literatura relacionada a bancos de tecidos neoplásicos, no período de 1969 a 2005 . Descreve a captação, armazenamento das amostras e o histórico do doador. $\mathrm{O}$ banco de tumores com um protocolo eficiente permite armazenar amostras de tecido normal e neoplásico, além de registrar dados referentes a pacientes com lesões neoplásicas. Além disso, possibilita o fornecimento, aos pesquisadores em câncer, de amostras de tecido em condições ideais para a pesquisa.

Descritores - Bancos de tecidos/organização \& administração; Bancos de tecidos/tendências; Neoplasias ósseas; Protocolos; Neoplasias/patologia; Oncologia/métodos; Comportamento cooperativo

\section{ABSTRACT}

A Tumor Bank with systematic organization of data allows for the carrying out of cancer research with sound and scientific conclusions. The need thus arises for a specific protocol whose main advantage would be that of adding qualified donor information to tumor samples used in research. The purpose of this study was to develop a simple, reliable, and replicable 
procedures protocol to acquire and store samples of musculoskeletal tumors. The basis for the planning of this protocol comprises the information gathered in the literature relating to tumor tissue banks from 1969 to 2005. The paper describes the capture, storage, and donor background. The tumor bank with an efficient protocol allows to store both healthy and neoplastic tissue, and to record information relating to patients with neoplastic lesions. Furthermore, it enables supplying tissue samples in ideal research conditions.

Keywords - Tissue banks/organization \& administration; Tissue banks/trends; Bone neoplasms; Protocols; Neoplasms/pathology; Medical oncology/methods; Cooperative behavior

\section{INTRODUÇÃO}

O interesse no campo do conhecimento e da pesquisa dos tumores conservados em banco de tecidos criopreservados vem de longa data. No momento da ciência, os principais objetivos dos bancos de tecido neoplásicos são as investigações em biologia molecular. Entre os benefícios, destacam-se a identificação de rearranjos clonais de genes e a sobre-expressão de alguns oncogenes. Com o desenvolvimento das técnicas da patologia molecular que permitem realizar estudos de expressão gênica, é fundamental para pesquisadores em câncer a utilização de tecidos neoplásicos humanos em condições ideais de armazenamento e obtidos de modo ético. Com protocolos bem definidos, uma rede de bancos de tumores (RBT) tem como objetivo suprir os pesquisadores com amostras de tumor ou outros tecidos de pacientes com câncer, acompanhadas do maior número possível de informações desses pacientes.

O desenvolvimento do banco de tumores (BT), com organização sistematizada das informações, permite a elaboração de pesquisas em câncer com conclusões sólidas e científicas. Com esse objetivo surge a necessidade de um protocolo específico. A principal vantagem seria a de agregar, às amostras tumorais em perfeito estado para pesquisa, informações qualificadas sobre o doador.
O objetivo desta publicação é a divulgação de um protocolo de procedimentos simples, confiáveis, reprodutíveis e factíveis em nosso meio para obtenção e armazenamento de amostras de tumores primários malignos e benignos e tumores secundários que acometem o sistema músculo-esquelético.

\section{MÉTODOS}

O planejamento deste protocolo tem como base dados extraídos da literatura. A combinação de dados demográficos com nome, sexo, idade, profissão, história familiar de doença tumoral, início dos sintomas, tratamento prévio, localização do tumor, diagnóstico inicial após laudo do médico patologista, entre outros, proporcionou sua criação num formato próprio para a inserção dos dados de maneira digital, armazenados e organizados em uma tabela de dados Microsoft Excel $^{\circledR}$.

O protocolo (tabela 1) foi desenvolvido por uma equipe multidisciplinar composta por médicos da Ortopedia, Genética, Anatomia Patológica e Oncologia da Escola Paulista de Medicina e aprovado pelo Comitê de Ética e Pesquisa da instituição.

O procedimento é realizado com o paciente anestesiado ou sob bloqueio regional no centro cirúrgico.

A anti-sepsia deve ser realizada e campos cirúrgicos estéreis devem delimitar a área a ser biopsiada. A coleta do material deve ser realizada com trefinas ou através de biópsias abertas.

O protocolo define que o material deverá ser obtido em dois momentos distintos, no ato da biópsia, quando se obtém tecido virgem de tratamento e, posteriormente, no momento de ressecção cirúrgica do tumor. Os pacientes que desenvolveram recidiva local ou metástases e que forem submetidos à biópsia ou ressecção dessas lesões também terão essas amostras armazenadas no banco de tumor.

A coleta de amostras de tecido ósseo é realizada com a agulha de Jamshidi nas áreas comprometidas pelo tumor. A avaliação prévia da lesão por exames de imagem direciona a biópsia para as áreas mais representativas do tumor. Os fragmentos removidos devem proporcionar material para o estudo anatomopatológico e para estudo genético, respeitando-se todos os preceitos de uma biópsia adequadamente realizada. O tama- 
nho mínimo adequado para as amostras que serão armazenadas em banco deve medir $0,5 \times 0,3 \times 0,3$ centímetros.

Um mínimo de três cilindros ósseos deve ser enviado para o patologista e três cilindros ósseos serão armazenados no banco de tumores.
$\mathrm{O}$ armazenamento deve ser realizado em recipientes plásticos (tubos de Ependorff) resistentes a ultrabaixa temperatura $\left(80^{\circ}\right.$ Celsius negativos), com capacidade volumétrica de dois mililitros.

$\mathrm{O}$ armazenamento é dividido em primário e definitivo:

TABELA 1

Protocolo do Banco de Tecido Neoplásico

\section{A) Dados de identificação do doador}

1. Nome: Número:

Data da captação: Hora:

Registro do doador:

Sexo: ( ) Masculino ( ) Feminino

Idade: Cor:

Raça: Naturalidade:

Nacionalidade:___ Profissão:

2. História familiar de tumor maligno: ( ) não ( ) sim Qual?

3. Diagnóstico presuntivo:

4. Quimioterapia prévia: ( ) não ( ) sim no de ciclos: Esquema de quimioterapia:

Droga(s) utilizadas:

5. Radioterapia prévia: ( ) não ( ) sim noo de sessões: Dose:

Região anatômica irradiada:

6. Tecido captado: ( ) Biópsia Data: Hora: ( ) Cirurgia Data: Hora:

7. Diagnóstico definitivo:

8. Tumor: ( ) Primário virgem de tratamento

( ) Primário pós-tratamento neo-adjuvante

( ) Recidiva local

( ) Metastático

9. Estágio (Enneking):

- Benigno: () IA () IB ( ) IIA ( ) IIB ( ) IIIA ( ) IIIB

- Maligno: () IA ( ) IB ( ) IIA ( ) IIB ( ) IIIA ( ) IIIB

10. Sarcoma de partes moles (AJCC $6^{\text {a }}$ ed):

( ) I ( ) II ( ) III ( ) IV

11. Resposta histológica do tumor à quimioterapia pré-operatória (Huvos):

( ) Grau I (0-50\%) ( ) Grau II (50-90\%)

( ) Grau III (90-99\%) ( ) Grau IV (100\%)

12. Material infectado: ( ) não ( ) sim

Agente:

13. Houve captação de tecido normal do doador:

( ) não ( ) sim Qual?
B) Dados de identificação da amostra de tecido

1. Registro no banco de amostra de tecidos Número de amostras captadas:

Numero do doador: Endereço:

2. Estrutura captada:

Lado: ( ) Direito ( ) Esquerdo

- OSSO:

( ) Epífise proximal ( ) Metáfise proximal

( ) Diáfise ( ) Epífise distal ( ) Metáfise distal

( ) Osso chato ( ) Osso curto

- OUTROS TECIDOS: ( ) Pele ( ) Subcutâneo

( ) Fáscia ( ) Músculo ( ) Tendão ( ) Sinovial

( ) Nervo ( ) Outro:

\section{REGIÃO ANATÔMICA:}

3. Diagnóstico definitivo:

4. TUMOR: ( ) Primário ( ) Recidiva ( ) Metastático

5. Houve captação do tecido normal do doador? ( ) não ( ) sim Qual?

6. Resposta histológica do tumor à quimioterapia pré-operatória (Huvos):

( ) Grau I (0-50\%) ( ) Grau II (50-90\%)

( ) Grau III (90-99\%) ( ) Grau IV (100\%)

7. Quimioterapia prévia: ( ) não ( ) sim

№ de ciclos:

Nome(s) droga(s):

8. Radioterapia prévia:

( ) não ( ) sim № de sessões: Dose: Região anatômica irradiada:

9. Material Infectado: ( ) não ( ) sim Agente: 
A) Armazenamento primário: aquele que ocorrerá imediatamente após a obtenção das amostras que são colocadas nos tubos de Ependorff, identificados com seus respectivos registros e imediatamente mergulhadas em nitrogênio líquido, no tambor de transporte (198 Celsius negativos).

B) Armazenamento definitivo: ocorrerá quando retirarmos os tubos de Ependorff do tambor de nitrogênio líquido e os armazenamos na caixa plástica (figura 1). Imediatamente essa caixa é guardada no freezer de ultrabaixa temperatura $\left(80^{\circ}\right.$ Celsius negativos $)$, onde é mantida até sua utilização.

O preenchimento dos dados de identificação do doador bem como os dados de identificação da amostra de tecidos são de total responsabilidade do cirurgião oncologista.

\section{DISCUSSÃO}

Os tumores ósseos primários correspondem a $2 \%$ de todos os tumores clínicos e os sarcomas ósseos, a $0,6 \%$ dos tumores malignos. Constituem um sério problema clínico, apesar de sua raridade. Se acrescentarmos a esse número as metástases ósseas, teremos um número significativo de neoplasias acometendo o esqueleto.

Com o desenvolvimento das técnicas de patologia molecular, que permitem estudos da expressão gênica com transcendência clínica, é nos dias de hoje de suma importância a utilização do tecido neoplásico humano nas pesquisas em câncer ${ }^{(1)}$.

O osteossarcoma é o sarcoma primário do osso mais comum, representando aproximadamente $20 \%$ de todos os sarcomas. Sua etiologia é desconhecida, ocorrendo com maior frequiência nas crianças e nos adolescentes. Sua gênese e progressão devem ser determinadas predominantemente por fatores genéticos ${ }^{(2)}$. Outros tumores primários são menos freqüentes, sendo o segundo em incidência o condrossarcoma e o terceiro o tumor de Ewing ${ }^{(3)}$.

Baseados na literatura e movidos pela idéia de armazenar tecido neoplásico para estudo, iniciamos a elaboração de um protocolo amplo com dados clínicos e cirúrgicos, a fim de criarmos um banco de tumores (BT). A organização das informações obtidas foi objetiva e

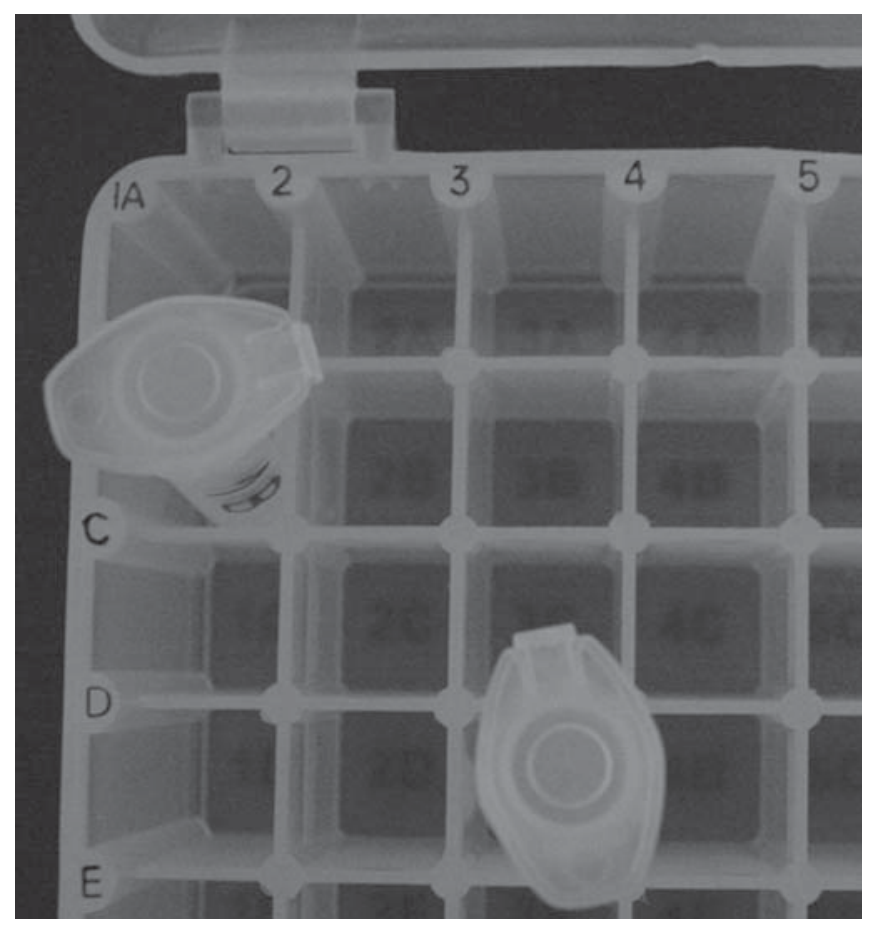

Figura 1 - Caixa contendo os tubos de Ependorff que são resistentes à ultrabaixa temperatura

direta, para facilitar a compreensão e a utilização do protocolo pelo usuário. Nosso principal objetivo é o de fornecer amostras de tecidos tumoral e normal, obtidos de pacientes portadores de neoplasias malignas e benignas, para os pesquisadores em câncer. Nossa visão é a de que esse material proporcione melhor conhecimento dos mecanismos básicos envolvidos na gênese, na evolução e, principalmente, na avaliação de resposta das neoplasias ao tratamento instituído.

A idéia de utilizar uma terapêutica que atinja somente as células neoplásicas e a identificação de marcadores capazes de distinguir pacientes sensíveis e pacientes resistentes à terapêutica de primeira linha são também objetivos da criação do banco de tecidos.

A constituição de um BT implica algumas exigências, tais como, condições ideais de coleta e imediato congelamento da amostra. Esse período entre a coleta da amostra e o congelamento é de importância fundamental para a viabilidade do tecido, permitindo a análise genética do material.

A história completa do doador é imprescindível para o banco de tumor. 
Decidimos, em nosso Serviço, concentrar nossos estudos e o desenvolvimento das técnicas de armazenamento em amostras de alguns tumores bem catalogados, principalmente o osteossarcoma ${ }^{(4)}$.

No que se refere ao armazenamento dos tumores, há vantagens e desvantagens no congelamento em freezer e no nitrogênio líquido. Os benefícios do congelador a $80^{\circ}$ Celsius negativos são a possibilidade de armazenar cerca de 15.000 tubos de Ependorff de 2ml, o fácil acesso aos exemplares e a menor infra-estrutura necessária. No entanto, são desvantagens o preço elevado, a fragilidade desses equipamentos e sua dependência da energia elétrica.

Quando analisamos o armazenamento no nitrogênio líquido, evidenciamos a dificuldade no acesso aos exemplares e a necessidade de manutenção constante do nível de nitrogênio. As vantagens são a conservação em nitrogênio líquido a $196^{\circ}$ Celsius negativos e sua independência da energia elétrica ${ }^{(1,4)}$.

Em nosso protocolo denominamos como armazenamento primário o congelamento em nitrogênio líquido; este é realizado imediatamente após a obtenção do exemplar, sem prejudicar o diagnóstico do paciente. $\mathrm{O}$ armazenamento definitivo é o acondicionamento no freezer a $80^{\circ}$ Celsius negativos.

Apoiados nos conceitos estabelecidos pela literatura e embasados em nossa experiência nas condições de nossa estrutura atual, definimos ofreezer a $80^{\circ} \mathrm{Cel}-$ sius negativos para o armazenamento definitivo.

No que se refere ao protocolo de registro dos dados dos doadores, é imperioso o registro de informações básicas, como sexo, idade, diagnóstico clínico e histopatológico, classificação TNM, diferenciação entre tumor primário, metastático ou recidivante, anamnese, antecedentes de tratamentos, seguimento pós-operatório, grau histológico, tipo de amostra e agentes infectantes, entre outros ${ }^{(1,4-9)}$.

A anotação precisa da estrutura captada foi mais um item adicionado, uma vez que este protocolo é dirigido para um banco de tumores do sistema músculoesquelético. Este dado informa o osso e sua área anatômica e ou tecidos moles captados. O nome e o registro do paciente doador também foram acrescentados, pois acreditamos que deva haver um link entre BT e os pes- quisadores em caso de novas descobertas que poderiam de alguma forma beneficiar o doador.

No que tange à biossegurança, são escassos os dados na literatura. Apenas Morente( ${ }^{(1)}$ e Sastre-Garau ${ }^{(4)}$ demonstraram alguma consideração sobre o assunto. O primeiro apenas salienta os riscos, enquanto o segundo aconselha que a equipe envolvida trate todos os exemplares como se estivessem contaminados. Há riscos inerentes à manipulação das amostras biológicas que poderiam estar infectadas por agentes patogênicos, como, por exemplo, HIV, HBV e BK ${ }^{(4)}$. Nossa conduta está de acordo com Morente ${ }^{(1)}$, uma vez que ainda não é possível assegurar de forma plena a ausência de agentes infecciosos mediante testes específicos de todos os doadores.

Os benefícios oferecidos pelas pesquisas com tecidos humanos tumorais ou normais, oriundos de doadores, não podem deixar de lado a séria e complexa questão ética e médico-legal. Toda informação fornecida deve ser preservada, de modo a não haver identificação do doador ${ }^{(1,9-13)}$.

\section{COMENTÁRIOS}

1) O banco de tecidos neoplásicos possibilita organizar dados referentes a pacientes com lesões neoplásicas. Este deve fornecer o maior número possível de informações sobre o doador. Um dos principais objetivos é ter capacidade de prover os pesquisadores em câncer com amostras de tecido neoplásico e normal em condições ideais para a pesquisa.

2) O doador deve ser mantido no anonimato, mas precisa ocorrer um link entre o BT e os resultados das pesquisas, propiciando ao paciente todos os benefícios oriundos das pesquisas com seus tecidos.

3) Os exemplares de tecido humano devem ser manipulados com precaução, pois podem conter agentes infecciosos.

4) A captação de tecido, tanto neoplásico como normal, não pode prejudicar o paciente nem interferir em seu diagnóstico.

5) O congelamento primário deve ser feito o mais breve possível, dentro dos primeiros dez minutos após a captação do material. 


\section{CRÍTICA}

Este é um artigo bem escrito, bem elaborado e de bastante utilidade para divulgar a importância de um Banco de Tecidos Neoplásicos.

A publicação deste artigo será de grande utilidade para os Serviços que pretendem trabalhar em pesquisas sobre neoplasias.

\section{José Donato de PRÓSPERO}

Professor Titular e Livre-Docente de Anatomia Patológica

do Departamento de Ciências Patológicas da Faculdade de Ciências Médicas da Santa Casa de São Paulo

\section{REFERÊNCIAS}

1. Morente M. The CNIO Tumour Bank Network [Internet]. Spain: Centro Nacional de Investigaciones Oncológicas, c2000. Available from: http://www.cnio.es/es/progamas/ progtumor01.htm.

2. Fuchs B, Zhang K, Schabel A, Bolander ME, Sarkar G. Identification of twenty-two candidate markers for human osteogenic sarcoma. Gene. 2001;278(1-2):245-52.

3. Jesus-Garcia Filho R. Diagnóstico dos tumores ósseos e sarcomas de partes moles. In: Jesus-Garcia Filho R. Diagnóstico e tratamento de tumores ósseos. Rio de Janeiro: Elsevier; 2005. p. $1-54$.
4. Sastre-Garau X. Banque de tumeurs cryo-préservées dans le laboratoire d'Anatomie Pathologique. Ann Pathol. 1995;15(4): 233-4.

5. Spaventi R, Pecur L, Pavelic K, Pavelic ZP, Spaventi S, Stambrook PJ. Human tumour bank in Croatia: a possible model for a small bank as part of the future European tumour bank network. Eur J Cancer. 1994;30A(3):419.

6. AIDS tumor bank. Science. 1995;270(5242):1571, 1573.

7. Anderer U, Nöhren H, Koch I, Harms D, Dietel M. [Aufbau der Kindertumorzellbank der Gesellschaft für Pädiatrische Onkologie und Hämatologie (GPOH)]. Klin Padiatr. 1998; 210(1):1-9. German.

8. Adam D. Online tumour bank aims to offer ready route to tissues. Nature. 2002;416(6880):464.

9. Chu TY, Hwang KS, Yu MH, Lee HS, Lai HC, Liu JY. A research-based tumor tissue bank of gynecologic oncology: characteristics of nucleic acids extracted from normal and tumor tissues from different sites. Int J Gynecol Cancer. 2002; 12(2):171-6.

10. Coupland LA, Cooke-Yarborough CM, Dalla-Pozza L. The New children's hospital tumour bank. Med J Aust. 1999; 170(6):284-5.

11. Thomas GA, Williams ED, Becker DV, Bogdanova TI, Demidchik EP, Lushnikov E, et al. Chernobyl tumor bank. Thyroid. 2000;10(12):1126-7.

12. Balleine RL, Humphrey KE, Clarke CL. Tumour banks: providing human tissue for cancer research. Med J Aust. 2001; 175(6):293-4.

13. Oosterhuis JW, Coebergh JW, van Veen EB. Tumour banks: well-guarded treasures in the interest of patients. Nat Rev Cancer. 2003;3(1):73-7. Review. 